\title{
Apuntes para unA NECROlogía de LA MUERTE
}

\author{
Luis Antonio Sánchez Trujillo
}

Resumen: Sacralizar la muerte ha sido una manera común de otorgarle sentido. Actualmente,, además de la sacralización que resurge en creencias como La Santa Muerte, asistimos a una negación-mercantilización que nos lleva a no mencionar siquiera la muerte por temor a invocarla. Desde otra perspectiva el discurso oficial del Estado se ha apropiado de la muerte como una estrategia de control, pues el temor de ser atacados, la vulnerabilidady violencia continua nos hacen depositar en el Estado la capacidad de protegernos.

Palabras clave: muerte, Santa Muerte, mercantilización, institucionalización, conciencia de muerte.

Enviado a dictamen: 28 de enero de 2008

Aprobación: 04 de junio de 2008.

Luis Antonio Sánchez Trujillo, psicólogo clínico, becario del proyecto de Migración y Género del CESMECA-UNICACH, estudiante de la Maestría en Ciencias Sociales y Humanísticas de la misma institución, diplomado en teoría e investigación de género por la UNACH, especialidad en terapia centrada en el cliente por el Centro Gestalt de Morelia, especialidad en terapia holística por el CETEOH; correo electrónico: migracionygenero@gmail.com.
Abstract: To transform death to the sacred, has been the common way togrant some sensetoitsexperience, but at the present time, inaddition to thisstrategy, that rises up and is recreated are beliefs like "SantaMuerte". We are attempting a negation and to a process of commercializing that take us to a position of not to mention it, because of the fear of invoking it. From another perspective, the official doctrine of the State has appropriated the use of the death as a strategy of control. The dread of being attacked, the vulnerability that the situation of naturalized and constant violence leads us to place only in the State, the ability to protect us.

Key words: death, Santa Muerte, mercantilation, institutionalization, death's conscience.

E stamos muriendo. No hay más que este continuo despeñarse hacia lasfauces del espejo del vampiro. Hacia una nada cuya respuesta es una copa rebosante de promesas dudosas, que es de continuo apurada para consolar al cuerpo de su destino inminente.

Que la muerte obsesione a la humanidad no es extraño y es comprensible que ésta busque desesperadamente en mitos, religiones, tradiciones y en esotéricos rumbos otorgar sentido al hecho desnudo y doloroso de que morimos. Sacralizar la muerte ha sido la manera común de otorgarle sentido y la institución religiosa se ha erigido en la encargada de guardarla y trasmitirla. Pero en la actualidad, además de la sacralización, asistimos a un proceso de negación-mercantilización que 
nos lleva a no mencionar siquiera la muerte por temor a invocarla. Desde otra perspectiva, el discurso oficial del Estado se ha apropiado del uso de la muerte como estrategia de control, pues el temor de ser atacados y la vulnerabilidad nos hacen depositar en el Estado la capacidad de protegernos.

La muerte se afirma y camina entre palabras vivas para dar cuenta de su hecho incognoscible, en el que todo es supuesto e incertidumbre; la única certeza es que a todos ocurrirá. Pese a ello, la mayor parte del tiempo, nuestros pasos transitan en calma, alejados de la espada de Damocles ${ }^{1}$ que de continuo nos persigue. Hace falta muchas veces un acontecimiento que rompa con la cotidianeidad para recordarnos la finitud que nos acompaña.

Al respecto Freud, en De guerra y de muerte, escribió:

Hemos manifestado la inequívoca tendencia hacer a un lado la muerte, a eliminarla de la vida. Hemos intentado matarla con el silencio [...] La muerte propia no se puede concebir; tan pronto intentamos hacerlo podemos notar que en verdad sobrevivimos como observadores. Así pudo aventurarse en la escuela psicoanalítica esta tesis: En el fondo, nadie cree en su propia muerte, o, lo que viene a ser lo mismo, en el inconsciente cada uno de nosotros está convencido de su inmortalidad (Freud, 1915: 72).

Cabe preguntarse si tal negación de la muerte propia es algo inherente a la naturaleza humana o, por el contrario, sólo es explicable en condiciones histórico materiales especiales. El anhelo de inmortalidad freudiano sería la consecuencia lógica de una sociedad que prioriza un sistema ético y de valores en el que no sólo la muerte es el sin sentido universal, sino que también la vida se transforma en una continua repetición alienada en la que no somos nada más que "aspirantes a propietarios", como sugiere Marx.

Grof (2006) plantea que el concepto actual de la muerte y la reacción de los moribundos, caracterizada por una represión y una negación masivas, parece ser producto anexo de una industrialización que crece rápidamente, con un acento excesivo sobre el pragmatismo, una filosofía materialista y una orientación general hacia el éxito y el triunfo.

Sin embargo, tal concepción y comportamiento ante la muerte no ha sido invariable a lo largo de la historia ni mucho menos entre la diversidad de culturas, quienes ofrecen una enorme variedad de marcos de referencia desde los cuales la vivencia de la muerte se vuelve a significar, poblándose de las interpretaciones más diversas.

Philipe Ariès, en Elhombre ante la muerte (1975), estudió los cambios en la actitud del hombre occidental frente a la muerte durante los últimos dos mil años. Este autor tomó como referencia cuatro elementos psicológicos:

1. La conciencia de sí.

2. La defensa de la sociedad contra la naturaleza salvaje.

3. La creencia en la sobrevida.

4. La creencia en la existencia del mal.

Al estudiar las variaciones de estos cuatro elementos distinguió, a lo largo de la historia de Occidente, cinco modos diferentes de entender el fenómeno de la muerte. La primera etapa, que duró aproximadamente hasta el siglo XII, fue de la muerte amaestrada o domesticada: la gente moría advertida. El moribundo esperaba la hora de la muerte en su lecho sin lamentos exagerados. La muerte era una ceremonia organizada. La habitación del moribundo se transformaba en un lugar público. Todos estaban allí: familiares, amigos, vecinos y niños. El ceremonial estaba despojado de todo dramatismo y emociones excesivas. El propio moribundo era el encargado de dirigir y llevar adelante los ritos de esas reuniones; algo así como un maestro de ceremonias. El drama no es personal sino colectivo, pues la comunidad queda, de alguna manera, debilitada con la desaparición de uno de sus miembros. 
A partir del siglo XII comienza un nuevo período. En la etapa anterior había una concepción colectiva del destino: el hombre padecía en la muerte una de las grandes leyes de la especie y no soñaba ni con sustraerse de ella ni con exaltarla. Ahora, se introduce la preocupación por la particularidad de cada individuo con referencia al Juicio Final.

En la escatología de los primeros siglos del cristianismo, los muertos que pertenecían a la Iglesia se adormecían y reposaban hasta el día del Segundo Advenimiento, del gran retorno, cuando se despertarían en la Jerusalén celestial (en el Paraíso). En esta concepción no había lugar para la responsabilidad individual y para un balance de las buenas y malas acciones. Pero desde el siglo XII encontramos "la resurrección de los muertos, la separación de los justos y los condenados; el juicio, el pasaje de las almas por el arcángel San Miguel".

En los siglos XV y XVI, el juicio ya no se sitúa en el fin de los tiempos, sino en la habitación del moribundo, en la inminencia de su muerte. Se trata de una prueba que consiste en una última tentación. El moribundo verá toda su vida y será tentado, ya sea por la desesperación de sus faltas, por la vanagloria de sus buenas acciones o por el amor apasionado a las cosas y los seres. Su actitud, en el relámpago de ese momento, borrará de golpe los pecados de toda su vida, si rechaza la tentación, o, si cede, anulará todas sus buenas acciones. Es clara la oposición entre la seguridad del rito colectivo y la inquietud de una interrogación personal. Sin embargo, un rasgo de la muerte amaestrada se mantuvo intacto y aun se acentuó: el papel del moribundo, que sigue estando en el centro de la acción, que preside como antaño y determina por su voluntad.

A partir del siglo XVIII el hombre occidental exalta la muerte, pretende que sea impresionante y acaparadora. Pero ya no está tan preocupado por su propia muerte: la muerte romántica es la del otro. La ceremonia en el lecho, comandada por el moribundo y en presencia de un vasto público persiste pero algo ha cambiado. En el siglo XIX una pasión nueva se apodera de los asisten- tes. La emoción los agita, lloran, rezan, gesticulan. No se niegan para hacer los gestos dictados por el hábito pero los ejecutan despojándolos de su carácter vulgar y consuetudinario. Como si fueran inventados por primera vez, como si fueran espontáneos, inspirados por un dolor apasionado y único. La sola idea de la muerte conmueve. Los sobrevivientes aceptan con mayor dificultad la muerte del otro.

Llegado el siglo XX la Primera Guerra Mundial dispara un cambio radical: a partir de entonces la muerte tiende a ocultarse y se transforma en algo vergonzoso y en objeto de censura. Una forma absolutamente nueva de morir ha aparecido en el curso del siglo XX, en algunas de las zonas más industrializadas del mundo occidental. La sociedad no tiene pausas pues la desaparición de un individuo no afecta su continuidad. En la ciudad todo sigue como si nadie muriese. Estamos en la época de la muerte prohibida.

El moribundo es privado de su muerte. Antes la información sobre la inminencia de la propia muerte era un derecho inalienable. Hoy, la verdad del estado del enfermo debe serle ocultada. Antes lo horroroso era la muerte súbita, sin posibilidad de prepararse, el moribundo no debía saber que lo era. Ahora, ya no hay lugar para las grandes demostraciones de melancolía y tristeza y, si se producen, deben ocurrir sin que el enfermo lo note; ya no se muere en casa rodeado de público, sino en los hospitales, muchas veces en la soledad de una sala de terapia intensiva. La gente muere a escondidas.

El profundo estudio historiográfico de Ariès muestra a la muerte como una construcción social cuyas transformaciones van de la mano de los cambios históricos y culturales. En este sentido, la ética que impregna las visiones mercantilizadas del sistema-mundo contemporáneo se han tornado causa estructurante de la vivencia de muerte. En nuestro país, dicha estructuración se origina en gran medida en el proceso de colonización, durante el cual con la persecución sistemática de todo aquello que tuviese el más ligero parecido con las cosmovisiones 
y cultos prehispánicos, casi se extinguió por completo las creencias de los pueblos indígenas, y muchos de los ritos antiguos se fusionaron y adquirieron nuevas significaciones como resultado de la evangelización católica. Como consecuencia de tal amalgama, el culto a la muerte se sumergió en un prolongado letargo, del que los procesos post revolucionarios lo rescatan para presentarla como elemento de cohesión, de identidad que caracteriza al pueblo mexicano. Octavio Paz, en El laberinto de la soledad (1999), postula un elemento necrófilo inherente a la cultura mexicana que, en gran medida, limita nuestras posibilidades de desarrollo.

Independientemente de la cuestionada idea de Paz, en la actualidad existe una marcada tendencia a desaparecer la muerte, a encubrirla en lo que parece un patológico intento de escapar de ella. En otros casos, la manera de conjurarla ha seguido el camino de la deificación, de la proyección del imago ${ }^{2}$ de la muerte como figura sacralizada y del imaginario social instituido. De esta forma se torna poderosa y capaz de salvarnos de ella misma. Tal es el caso del fenómeno religioso de La Santa Muerte que, en nuestro país y en otros, avanza a un ritmo tal que su culto es comparable ya al guadalupano.

Existen dos versiones para explicar el origen de este culto (presentado por quienes no lo profesan, como algo propio exclusivamente de narcotraficantes y personas que se mueven al margen de la ley). Homero Aridjis, en su novela La Santa Muerte, lo presenta como una derivación del culto prehispánico a las deidades de la muerte que, desde los mexicas y mucho antes, habría de permanecer oculto en la religión católica impuesta durante la Colonia, para renacer en la actualidad con mayor fuerza. Para Katia Perdigón (Lajornada, 2004) tal noción resulta del todo errónea, pues La Santa Muerte posee elementos que la ligan a un origen grecolatino, como la túnica, la guadaña y el reloj de arena, y que son ajenos a las representaciones prehispánicas. Para esta investigadora el culto tiene su origen en los años cincuenta, y se populariza a partir de 1965, cuando hace su aparición en el estado de Hidalgo.
Para la mayor parte de los estudiosos del tema, el auge de este culto es el resultado de la precarización de las condiciones de vida en nuestro país. El aumento de la violencia y las crisis continuas han llevado a la población a buscar consuelo y solución a sus problemas fuera del Estado y de la Iglesia Católica.

Desde esta perspectiva, la sacralización de la muerte tomaría la forma de una sublimación ${ }^{3}$ de los anhelos irresueltos de la población, que vuelven fetiche y transforman en objeto de adoración aquello que es más temido. En tal deseo irreverente y blasfemo, que rompe con el nomos construido en torno al imago de muerte, es posible encontrar el anhelo del imaginario radical que, en su insatisfacción ante los pobres objetos noéticos significantes ${ }^{4}$ instituidos para la muerte, busca la ruptura, la creación de una representación renovada desde lo ilegal y desde lo que está prohibido en el discurso.

Si el hartazgo ante la institucionalización de la muerte es el punto de origen de su sacralización, el efecto de ruptura es amortiguado por el sistema, pues surgen de inmediato nuevos y autodeclarados gurús, así como formas e instituciones que se autonombran portadoras de la verdad en torno a la nueva representación. Deinmediato, la imagen de La Santa Muerte es dogmatizada, tornando doxa ${ }^{5}$ todo intento de crear una nueva representación; se crean ritos y fórmulas que, se asegura, son las verdaderas, las efectivas, sin las cuales será imposible atraerse a los favores de esta nueva deidad, cuya mayor peculiaridad es que no exige para con sus fieles una ética especial, un comportamiento virtuoso o respetuoso hacia los demás, como acontece con otras figuras santificadas dentro de la Iglesia Católica; por el contrario, es posible atraer los favores de La Santa Muerte con dádivas: quienes le rinden culto saben que hay que mantenerla "contenta" llevándole velas, flores, incienso, alimentos, vino, pan, etcétera; con un precio, porque todo se incorpora al mercado y arroja ganancias.

En el culto de "La Niña Blanca", como muchos la llaman, el papel que ha jugado la Iglesia Tradicional MéxicoEstados Unidos, dirigida hábilmente por David Romo, 
el arzobispo primado de la misma, ha sido fundamental. $\mathrm{Al}$ incorporar la imagen y reconocerla como "Santa", ha facilitado el camino del crecimiento de su devoción y ha fijado los parámetros para la institucionalización y reproducción del culto, cuyo espacio de celebración es el Santuario Nacional de la Santa Muerte, en la calle Bravo número 35, en un barrio popular de la colonia Venustiano Carranza, en el Distrito Federal. El número de fieles pertenecientes a la Iglesia Tradicional crece cada día y para esto ha colaborado, en gran medida, la oposición de la Iglesia Católica a La Santa Muerte, pues se le considera un pecado y una aberración de la religiosidad tradicional. Romo precisa que su culto tiene origen en la religión católica antigua y que nada tiene que ver con las prácticas esotéricas que recurren al uso de colores u oraciones para pedir cosas materiales, saldar venganzas o conseguir amores: "Aquí el ritual consiste en bendecir la imagen y ya, la devoción a La Santa Muerte es de oración y reflexión, porque la muerte es vida" (La Jornada, 2004).

Desde otra cara de la moneda, muchas personas niegan la autoridad que la Iglesia Tradicional se atribuye sobre la posesión de la verdad acerca de La Santa Muerte; sugieren que ellas poseen el conocimiento heredado desde generaciones pasadas para enseñar a otros; entre sus conocimientos se entremezclan la magia y el esoterismo y enseñan que dependiendo de la petición del fiel debe ser el color de la muerte que se debe escoger para colocar en el altar: blanca para salud; negra para fuerza y poder; morada para abrir caminos; café para invocar espíritus del más allá; verde para mantener unidos a los seres queridos; roja para el amor y la amarilla para la buena suerte. Se dice que el día oficial para celebrar a La Santa es el 15 de agosto, declarado como "Día de la Santa Muerte", aunque otros consideran que se le debe celebrar el dos de noviembre. A pesar de no existir un acuerdo unánime se organizan rituales similares a los cristianos, incluidas procesiones y oraciones para ganarse el favor de La Santa. Muchos erigen su propio altar en el hogar, oficina o negocio, para sentirse protegidos. Dicho altar consiste en una estatuilla, de 15 centímetros a tamaño humano, que está rodeada por ofrendas como arreglos florales, frutas, inciensos, vinos, monedas, dulces y golosinas, así como velas de diversos colores de acuerdo con la petición.

Lagente acudea La Santa Muerte para pedirle milagros o favores relacionados con el amor, la salud o el trabajo. También se le pide para fines malévolos, como la muerte de otras personas. Los simpatizantes suelen identificarse al portar algún dije o escapulario de La Santa, mientras que otros optan por llevar su figura tatuada de manera indeleble en la piel. El apego a esta creencia se ha extendido al territorio norteamericano con lainmigración de muchos de los creyentes, quienes afirman haber entregado su travesía a su "Santa" para que los cuide, llevando imágenes de ella entre sus ropas. Debido a esta creencia, La Santa prefiere no ser llamada por su nombre, se dice que agradece si es nombrada con alguno de sus apodos favoritos: "La Comadre", "La Bonita", "La Flaca", "La Señora" o "La Niña".

Para los fieles, la ropa que viste La Santa Muerte tiene un significado especial. La túnica que la cubre de la cabeza a los pies representa la forma en que ocultamos nuestra verdadera apariencia detrás de otra. Así como la tela cubre al esqueleto nosotros ocultamos, con nuestra carne, aquello que nos delata como humanos y que tratamos de disfrazar (pensamos que una cara bella lo es por la piel y el color, pero si escarbamos hallaremos la calavera que en poco se distingue, la que trae nuestro vecino mejor amigo o nuestro más odiado enemigo). De allí que la túnica sea el disfraz con que La Santa oculta el destino que todos llevamos en nuestro cuerpo. En la mayoría de las representaciones la túnica es blanca.

La Guadaña representa la justicia implacable del ser supremo que gobierna y rige la vida de todos; es la naturaleza misma que nos impone morir un día para cumplir con el ciclo iniciado al nacer. Al mismo tiempo, la hoz larga y siniestra indica que en el camino de la muerte no hay distinciones. Es signo de equidad y armonía.

El Mundo significa que la muerte no tiene fronteras; está en todo lugar y no distingue entre los diferentes hombres y mujeres que habitan el planeta, que es suyo. 
La Balanza es una clara alusión a la equidad, la Justicia y la imparcialidad. También representa la voluntad divina. Normalmente, la Balanza se usa para realizar un trabajo o para indagar la verdad sobre un suceso.

El reloj de arena es la medida de la vida sobre la tierra, y basta con girarlo para volver a comenzar. Esto es muy importante ya que la vida de todos es cíclica; la muerte es un cambio semejante a voltear el reloj y comenzar de nuevo.

Según el planteamiento de la restauradora Katia Perdigón, entrevistada en La Jornada (2004), el fenómeno surge en la década de los cincuenta, por medio de estampas que se vendían de manera casi clandestina en el mercado de Sonora, en el centro de la Ciudad de México. Ella no sabe quién las sacó, pero afirma que fue "con gente que estaba muy cerca de la muerte, como policías, basureros y sexoservidoras". Se rezaba a las estampas con cualquier oración católica y se las ponía en un altar con un vaso de agua, flores y una veladora.

Desde hace cinco años, "el ingenio de los vendedores" la convirtió en figura de culto. Como la demanda fue mayor se diversificaron los artículos: veladoras, escapularios, amuletos, oraciones para pedir favores materiales, hasta que la figura se convirtió en el principal artículo esotérico de consumo en el mercado de Sonora.

La base social del culto está integrada por personas de escasos recursos, excluidas de los mercados formales de la economía, de la seguridad social, del sistema jurídico y del acceso a la educación, además de un amplio sector social urbano y semirrural empobrecido. También le rinden culto personas que se encuentran fuera de la ley; la imagen ha sido encontrada muchas veces en altares de casas de narcotraficantes y criminales. Hay que destacar que parte importante del mercado religioso de La Santa Muerte está constituida por los ambulantes, sobre todo del Centro Histórico de la Ciudad de México, así como por los circuitos del narcomenudeo, redes de prostitución, maleantes, carteristas y desde luego una amplia población recluida en las instituciones penales, en donde es común encontrar altares en celdas y toda una cultura de adora- ción en torno a La Santa. Actualmente, también rinden culto a La Santa políticos, policías, militares y personas de las altas esferas económicas, lo que nos habla del creciente auge y propagación del fenómeno en nuestro país.

Es posible observar, tanto en la versión de la Iglesia Tradicional como en la de mercados y centros espiritistas, el mecanismo por medio del cual aquello que más se teme se sacraliza para controlarlo, evitarlo y usarlo como elemento de control que da poder por encima de otros. En todo caso la muerte, santa o no, se convierte en un "fantoche" del sistema, simple artículo que es posible comprar y cuyas dádivas son también adquiribles si se obsequia con los bienes y favores que el sistema mismo ha fijado como valiosos y correctos. La muerte está en venta, se ha capitalizado y para "ganársela" sólo hay que extenderle los mismos privilegios que a un invitado de quien se espera conseguir algo. Esta relación de compra-venta es en gran medida el resultado de la confluencia de la ética capitalista con las visiones heredadas de la muerte en nuestro país, en especial entre las clases populares de bajos recursos.

Pero, además de la notoria raíz económica que puede explicar la amplia difusión y el crecimiento del culto a la muerte (pues el capitalismo es un sistema que se caracteriza por la continua búsqueda de nuevos mercados y productos que vender), es en el proceso de resignificación donde se encuentra el cambio esencial. El sistema-mundo no sólo crea nuevos productos, requiere que para venderse se les considere necesarios; de manera indirecta, la ética capitalista fija, inconscientemente, la situación de inseguridad y dependencia que el pueblo mexicano vive, facilita la búsqueda de nuevas deidades que permitan expresar la precarización y la violencia, consecuencias de un sistema que se autonombra defensor de las libertades, mientras subyuga a la humanidady le impone una visión del mundo en la que toda felicidad sigue el camino de la competencia desmedida por la adquisición de riquezas.

A propósito de este evidente proceso de mercantilización de la muerte, Sogynal Rimpoché, monje tibetano y estudioso del fenómeno de la muerte, escribió: 
Descubrí que a la gente de hoy se le enseña a negar la muerte, y se les enseña que no significa otra cosa que aniquilación y pérdida. Eso quiere decir que la mayor parte del mundo vive o bien negando la muerte o bien aterrorizado por ella. El mero hecho de hablar sobre la muerte se considera morboso, y muchas personas creen que el sólo hecho de mencionarla es correr el riesgo de atraerla (Rimpoché, 1994: 26).

Este proceso de mercantilización se encontraría ligado con el desarrollo del sistema-mundo capitalista contemporáneo, que ha impregnado con una ética egotista y avariciosa los diversos campos de la vida humana; además de provocar que formas divergentes de expresión tengan que estar supeditadas a una capacidad de generar ganancias o desaparecer, como primitivismos que estorban el avance de la civilización.

En este sentido, el culto a La Santa Muerte, pese a su contenido plurirreligioso y controvertido, resulta provechoso, pues da cabida al desarrollo de un mercado en constante aumento de actividades y mercancías requeridas por sus fieles. Sin embargo, la imago de muerte dista mucho, en la actualidad, de ser representada totalmente por el fenómeno de sacralización, pues en otras esferas la negación de la muerte se vuelve un afán insatisfecho de placeres, justificados como deseo de "sorber hasta la última gota de vida" antes que ésta llegue a su fin. "Comamos y bebamos que mañana moriremos", dice el refrán, y despliega el sentido final de una sociedad que pretende el olvido del sinsentido, dentro de un sistema alienado, con una búsqueda incesante de placeres.

\section{Al respecto Erich Fromm escribió:}

El desarrollo de este sistema económico ya no quedó determinado por la pregunta: ¿Qué es bueno para el hombre?, sino la pregunta: ¿Qué es bueno para el desarrollo del sistema? Se trataba de ocultar lo enconado de este conflicto suponiendo que lo que era bueno para el desarrollo del sistema (o aun para una sola gran empresa) también era bueno para la gente. Esta interpretación se vio reforzada por una interpretación subsidiaria: que las cualidades mismas que el sistema requería de los seres humanos (egotismo, egoísmo y avaricia) eran innatas a la naturaleza humana; por ello, no sólo el sistema, sino la misma naturaleza humana las fomentaba; se suponía que las sociedades en que no existía el egotismo, el egoísmo y la avaricia, eran "primitivas", y sus habitantes eran como "niños". La gente se negó a reconocer que estos rasgos que habían dado el ser a la sociedad industrial no eran impulsos naturales, sino producto de las circunstancias sociales (Fromm, 2006: 4).

Ambas tendencias, la sacralización y el hedonismo, se instalan dentro de la ética del sistema, al crear nuevas necesidades. La lógica del mercado y la búsqueda de sentido se han encarnado en la identidad colectiva; las personas consideran que el capital es indispensable y se proyecta en la imago de muerte, que instituye un sentido mercantil a algo que es el sin sentido absoluto.

La alienación de la muerte puede leerse ya en Lamuerte de Ivan Ilich de León Tolstoi (2007), donde la vivencia de la propia muerte es ocultada a su protagonista, quien se entera de la inminencia de su fin por casualidad. Esta novela corta representa la negación de la muerte y el cambio en la moral burguesa de su tiempo, en el que la actitud de respeto ante la muerte ajena transita hacia la alienación; algo que no me puede pasar a mí; así las exequias se convierten en trámite social para los vivos en su mundo de apariencias.

En un talante similar Oliverio Girondo escribió:

La urgencia de liberarse de esta obsesión por lo mortuorio, hizo que cada cual se refugiara — según su idiosincrasia - ya sea en el misticismo o en la lujuria. Las iglesias, los burdeles, las posadas, las sacristías se llenaron de gente. Se rezaba y se fornicaba en los tranvías, en los paseos públicos, en medio de la calle [...] Borracha 
de plegarias o de aguardiente, la multitud abusó de la vida, quiso exprimirla como si fuese un limón, pero una ráfaga de cansancio apagó, para siempre, esa llama rara de piedad y de vicio (Girondo, 1966: 145).

La actitud ante la muerte varía, en nuestros días, entre una huida hacia placeres momentáneos o un temor profundo que se refugia en un rito alienado. Ambos casos representan en el fondo la necesidad del sistema por integrar la experiencia de la muerte en el habitus capitalista que a todos nos estructura.

La imago de muerte se convierte en una forma de control macro social cuando el Estado emplea el temor y las significaciones alienadas para justificar políticas de violencia y militarización; esto ha ocurrido en México, con la guerra contra el crimen organizado, en la que se pretende proteger al pueblo mexicano de la creciente inseguridad. Asíla reciente campaña de Felipe Calderón en los medios masivos es el ejemplo más evidente del uso de la muerte como estrategia de autovalidación, única vía por la que el Presidente ha podido legitimar su cuestionada elección presidencial en 2006; además, le ha permitido crear el Cuerpo de Fuerzas de Apoyo Federal, bajo su mando directo, el nueve de mayo de 2007; esto sin la anuencia del Congreso y violando la constitución (Artículo 73, fracción XIV); actos semejantes son comprensible sólo en un ambiente en el que se justifica la violencia, pues el temor a la muerte es explotado hábilmente y el uso de la fuerza se convierte en la única vía de restauración de un supuesto estado de derecho inalcanzable, en una sociedad polarizada y con profundas contradicciones sociales.

El uso del temor a la muerte por el Estado implica un peligro muy grande; el caso extremo lo representa Estado Unidos, con su política beligerante y de abierta imposición, justificada por el Presidente como única vía de proteger a su nación y al mundo del terrorismo y del crimen organizado.

Vivimos en una cultura necrófila que entroniza la muerte por la vía del silencio, y la oculta entre los titulares de los periódicos y en los noticieros, entre recrudecidas y morbosas imágenes que naturalizan la muerte ajena sin permitirnos reconocer la posibilidad de la propia finitud.

A las formas anteriores de experimentar la muerte hay que agregar el suicido, que deja ver lo absurda e inaceptable que es la vida para muchos en la actualidad; las estadísticas ${ }^{6}$ indican que este problema afecta cada vez más a la población joven, incluso a los niños.

En los años cincuenta Erich Fromm hizo notar, en Psicoanálisis de la sociedad contemporánea, que una medida alterna para medir el desarrollo humano, más allá de términos capitalistas de crecimiento económico, es el índice de alcoholismo y suicidios de una población; semejante estadística permitiría conocer el grado de satisfacción de las necesidades humanas; de verdadera felicidad y sentido que una sociedad ofrece a sus miembros.

El actual aumento en el porcentaje de suicidios en nuestro país es la más cruda fotografía del avance avasallador del sistema y sus estragos en las identidades de hombres y mujeres, quienes no encuentran más salida que la muerte en el vacío de una sociedad que les niega toda posibilidad de auténtico desarrollo.

La muerte propia es la única escapatoria en un mundo que privilegia la acumulación de capital como única realización, y en donde las relaciones personales se entablan sobre una base mercantil en la que sólo importa el beneficio personal, lo que lleva a una desconexión que vuelve extraños a los otros; morir se convierte en un acto de acusación ante la comunidad alienada.

Existe un trasfondo común en las experiencias y significaciones de la muerte que hemos tratado: la sustitución de una conciencia de muerte anclada en la necesidad humana de conferir un sentido subjetivo, diverso y trascendente a una experiencia que nos unifica a todos, por una reproducción alienada que convierte a la muerte en un fetiche del sistema.

La uniformidad de la experiencia de la muerte puede ser entendida como un elemento más de "avance de la insignificancia”, resultado de la institucionalización del 
imaginario social en torno del fenómeno de la muerte. ${ }^{7}$ Dicha institucionalización se torna conflictiva para quienes vivimos en una sociedad específica, al contradecir uno de los principios básicos con que el imaginario social instituyente funciona:

La sociedad puede hacer de la psique lo que quiera; volverla poligámica, poliándrica, monógama, fetichista, pagana, monoteísta, pacífica, belicosa, etcétera. Mirando más de cerca constatamos que ésta efectivamente es cierta, siempre que se cumpla una condición: que la institución ofrezca a la psique un sentido para su vida, y para su muerte (Castoriadis, 1997: 6).

La incapacidad de cubrir el sentido que la psique requiere para acoplar su funcionamiento interno al de una realidad reconocida como tal se convierte en continuo displacer, origen de angustia y ansiedad que socava, a la larga, las bases de la institución imaginaria y propicia el cambio, pues obliga a las sociedades a repensarse y a reconstruir sus visiones para restituirles el sentido requerido. Sin embargo, tal trasformación no ocurre en corto tiempo, porque a la innovadora fuerza de la psique se opone la institucionalización, lo que para Bourdieu es la doxa, la pasiva aceptación de las incoherencias del sistema, que se vuelven invisibles para los sujetos sociales atrapados por la ilusión e incapaces de propulsar el cambio.

La necesidad de sentido (que para Castoriadis es la característica fundamental de la psique y su punto ortogenético) es, paradójicamente, la fuente central de los conflictos neuróticos. La sociedad y sus instituciones son el resultado de la psique, que las crea en su afán de otorgar sentido a una realidad siempre recreada por el pensamiento. Como en el mito del Golem, las creaciones se vuelven contra su creador al obstaculizar el surgimiento de nuevos sentidos, de nuevas dimensiones de expresión de la psique, por su naturaleza, fuente inagotable de búsquedas y pulsiones. Las pulsiones, lejos de limitarse al concepto libidinal planteado por Freud, son un continuado anhelo de significación noética, ${ }^{8}$ como dice Víctor Frankl; esta búsqueda de sentido es la característica fundamental de la vida del ser humano y, en la capacidad de descubrirlo, se sentarán las bases del equilibrio emocional y mental. La finitud de nuestra existencia impone la necesidad de otorgar un sentido al sin sentido mismo, a la muerte; tal sentido conferido es un descubrimiento que vuelve a significar un hecho que ocurre a todos de una forma única, por lo que singularidad y responsabilidad serán dos elementos indispensables en la representación de la psique para que pueda integrar la experiencia de muerte: "la finitud, la temporalidad, no sólo es una característica esencial de la vida humana sino que es, además, un factor constitutivo del sentido mismo de la vida" (Frankl, 1998: 117).

La exigencia de conferir sentido a la muerte y la existencia del ser humano parten de la posibilidad y desarrollo de una conciencia de muerte; pero el sistemamundo contemporáneo ha deformado esta capacidad de conciencia, este darse cuenta de la finitud y de la continua posibilidad de la muerte, que se ha vuelto pornográfica, pues hablar de ella es tabú e incluso las celebraciones y rituales que la han acompañado durante siglos se vuelven simples días de venta. De manera paradójica la muerte alienada, una necrofilia presente en los medios como culto a la violencia, como forma de hablar de la muerte sin apropiarse de su verdadero significado, es una característica de nuestras sociedades. Así, en los diversas formas que la sociedad contemporánea ha designado como rituales y fórmulas válidas para vivenciar la muerte subyace el deseo de controlarla, de aplicar la fórmula del "poder sobre" que caracteriza a las relaciones verticales y desiguales sobre las que funcionan nuestras percepciones de la realidad; en tal herencia ética del capitalismo reside el núcleo de la imago de muerte contemporánea y sus diferentes significaciones, que retroalimentan el imaginario social.

Paralelamente a esta mercantilización, el duelo mismo, el proceso y asimilación de una pérdida, ha sido 
socavado: al negar la muerte se impide que le confiramos significados útiles, de los cuales sea posible obtener aprendizajes valiosos para la vida.

La negación de la posibilidad de la muerte nos hace llevar vidas cuyo sentido se basa casi por completo en el cumplimiento del destino socialmente construido. En un plano social, lo que nuestra alienada conciencia de la muerte implica es la reproducción de la ética capitalista sistémica; la posibilidad de existencia del sistema con sus contradicciones sólo es entendible porque la búsqueda de sentido que configura a la psique desde su centro (aquello a lo que Castoriadis ha llamado imaginario radical) se encuentra sometida y desvalorizada por una realidad que, al ser vivida como la única posible, niega cualquier intento por sustraerse a ella; así se impide a la psique su derecho radical hacia la libertad. Una vez negada la dimensión noética significante, las vías posibles se tornan predecibles: ya sea la pasiva aceptación de la realidad, con su neurosis cotidiana e infelicidad, que en casos extremos llevan a la locura, la violencia y la autodestrucción, o la revolución como apuesta creativa del imaginario radical que inventa y transforma posibilitando el cambio; esta última opción requiere condiciones materiales y acceso a capitales económicos, culturales y simbólicos que sólo están a la mano de una privilegiada minoría.

El reconfigurar los significados de la muerte, con nuevas y diferentes maneras de experimentarla, se vuelve un objetivo deseable y necesario en el camino del cambio ético y cultural, sin el cual es imposible plantear la posibilidad de una sociedad autónoma como representación del imaginario radical. La muerte puede transformarse en motor de vida si la llamamos a resucitar desde su olvidada tumba.

\section{Notas}

${ }^{1}$ El origen de la anécdota se localiza en una Historia de Sicilia escrita por Timeo de Tauromenio (c. 356-260 A.C.). Damocles fue un cortesano excesivamente adu- lador en la corte de Dionisio II, un tirano de Siracusa (Sicilia) del siglo IV A.C. Propagó que Dionisio era realmente afortunado al disponer de tan gran poder y riqueza. Dionisio, deseoso de escarmentar al adulador, se ofreció a intercambiarse con él por un día, de forma que pudiera disfrutar de primera mano su suerte. Esa misma tarde se celebró un opíparo banquete donde Damocles gozó siendo servido como un rey. Sólo al final de la comida miró hacia arriba y reparó en la afilada espada que colgaba atada por un único pelo de crin de caballo directamente sobre su cabeza. De súbito se le quitaron completamente las ganas de los apetitosos manjares y las hermosas muchachas, y pidió al tirano abandonar su puesto, diciendo que ya no quería seguir siendo tan afortunado. La espada de Damocles es una frase acuñada para ejemplificar la inseguridad en que se instalan aquellos que ostentan un gran poder, pues no sólo pueden perderlo de golpe, sino todo lo demás, incluso la vida.

${ }^{2}$ El termino imago lo empleo para dar cuenta de la representación construida que la sociedad crea para la muerte; en sí la muerte es inaprensible, sentido en perpetua creación y que forma parte del imaginario social.

${ }^{3}$ La sublimación es un mecanismo de defensa que permite transformar una pulsión inconsciente en una representación con un significado socialmente construido, lo que implica que no necesariamente se encarna en un acto positivo.

${ }^{4}$ Retomamos la visión de Cornelius Castoriadis para plantear este anhelo de significación noética como algo propio de la humanidad, un elemento central de la psique, pues la realidad es ante todo una significación creada para otorgar sentido y unificar una experiencia que de otra forma se torna ajena y amenazante.

${ }^{5}$ El concepto doxa es retomado por Bourdieu de Platón, y se refiere al conocimiento ingenuo, al sentido común que empuja a obrar de formas estereotipadas, en consonancia con los requerimientos del sistema, a manera de introyecciones que configuran el habitus.

${ }^{6}$ Según el INEGI, en 2004 ocurrieron 3 mil 324 suicidios, que representan un incremento de $3.2 \%$ con respecto a 
lo registrado en 1995, Veracruz es el estado con mayor incidencia, con $9.7 \%$ del total nacional de casos, seguido por Jalisco (9.5\%), Chihuahua (5.8\%), el Distrito Federal (5.7\%) y Nuevo León (4.7\%). En estas seis entidades se concentró $40.3 \%$ de los hechos registrados en el país, mientras que Tlaxcala sólo observó 19 casos y Guerrero 29. En promedio ocurrieron 104 suicidios por entidad federativa.

${ }^{7}$ Cada manifestación del pensamiento es un momento en un encadenamiento histórico y también, si bien no exclusivamente, su expresión. De la misma manera, sus manifestaciones son momentos del medio social (Castoriadis, 1997).

${ }^{8}$ La búsqueda del sentido de la vida constituye una fuerza primaria y no una "racionalización secundaria" de los impulsos instintivos. Este sentido es único y específico en cuanto es uno mismo quien tiene que encontrarlo; únicamente así logra alcanzar el hombre un significado que satisfaga su propia voluntad de sentido (Frankl, 1991).

${ }^{9}$ El poder sobre es explicado por Rowlands (1997) como poder "de suma cero"; cuanto más poder tiene una persona, menos tiene la otra. Es un instrumento de dominación cuyo uso puede verse en la vida personal de la gente y en sus comunidades.

\section{Bibliografía}

Aridjis, Homero, 2003, La Santa Muerte: sexteto del amor, las mujeres, los perros y la muerte, Alfaguara, México.

Ariés, Philippe, 1984, El hombre ante la muerte, Taurus, Madrid.
Bourdieu, Pierre y Louis Wacquant, 1995, Respuestas por una antropología reflexiva, Grijalbo, México.

Castellanos, Laura, 2004, "La Santa de los desesperados", en La Jornada, México, 9 de mayo, fotografías, José Carlo González, http://www.jornada.unam. mx/2004/05/09/mas-santa.html.

Castoriadis, Cornelius, 1997, "El imaginario social instituyente”, en Zona erógena, núm. 35, España.

Frankl, Viktor, 199l, El hombre en busca de sentido, Herder, España.

Frankl, Viktor, 1998, Psicoanálisis y existencialismo: de la psicoterapia a la logoterapia, Fondo de Cultura Económica, México.

Freud, Sigmund, 1985, De guerray de muerte, Obras completas, Psikolibro, en www.psikolibro.com.

Fromm, Erich, 2006, Tener y ser, Psikolibro, en www. psikolibro.com.

Girondo, Oliverio, 1996, Obras completas, Losada, Argentina.

Grof, Stanislav, 2006, El viaje definitivo: la consciencia y el misterio de la muerte, La liebre de marzo, España.

Lagunas, Icela, 2003, "Santa Muerte protectora del barrio", en El Universal, 12 de mayo, México.

Martínez, Óscar, 2007, "Cada Quién con su Santa Muerte”, en La Prensa Gráfica, http://www.laprensagrafica. com/enfoques/911284.asp,

Paz, Octavio, 1999, El laberinto de la soledad, FCE, México.

Rimpoché, Sogyal, 1994, El libro tibetano de la vida y de la muerte, Urano, Argentina.

Rowlands, Jo, 1997, Questioning Empowerment, Oxford, Oxfam, Estados Unidos.

Tolstoi, León, 2007, La muerte de Ivan Ilich, editorial Debolsillo, México. 